\title{
Fundamental Ideas as a Guiding Category in Mathematics Education-Early Understandings, Developments in German- Speaking Countries and Relations to Subject Matter Didactics
}

\author{
Andreas Vohns ${ }^{1}$
}

Received: 30 October 2014 / Accepted: 8 February 2016 / Published online: 1 March 2016

(C) The Author(s) 2016. This article is published with open access at Springerlink.com

\begin{abstract}
In its day-to-day regime the mathematics classroom is mainly focused on students' mastery of specific knowledge and skills currently at hand. But do they see the bigger picture? Do they get an appropriate idea of what mathematics is essentially about? Fundamental ideas have been a regularly proposed way to outline the bigger picture. That is, to provide both mathematics educators and students with several central themes that interconnect the different areas of mathematics and its applications. Such ideas should be able to guide the selection, organization and presentation of curriculum content and subsequently make mathematics more understandable for students.

This article aims to offer the English-speaking reader an overview of important stages in the specific development of the understanding of fundamental ideas within the German-speaking community of mathematics education. It embeds this line of research within the subject matter didactics tradition that this volume is dedicated to and it draws comparisons to and discusses relations between "Grundvorstellungen" and fundamental ideas.
\end{abstract}

Keywords Fundamental ideas · Didactic principles · History of mathematics education - subject matter didactics · Secondary Education

Andreas Vohns

Andreas.Vohns@aau.at

1 Institut für Didaktik der Mathematik, Alpen-Adria-Universität Klagenfurt, Sterneckstraße 15, 9020 Klagenfurt, Austria 


\section{Fundamentale Ideen als Leitkategorie in der Mathematikdidaktik - Frühe Zugänge, Entwicklungen im deutschprachigen Raum und Querverbindungen zur Stoffdidaktik}

Zusammenfassung Das „Alltagsgeschäft“ des Mathematikunterrichts konzentriert sich für gewöhnlich auf die gerade aktuell zu beherrschenden Wissensbestände und Fähigkeiten. Aber bekommen die Lernenden auch ein Bild vom Ganzen, eine Ahnung davon, worum es bei Mathematik im Kern eigentlich geht? Fundamentale Ideen sind ein verschiedentlich gemachter Vorschlag, ein Bild von Ganzen zu skizzieren, indem sowohl Lehrende als auch Lernende mit einigen „roten Fäden“ versorgt werden, die verschiedene Bereiche der Mathematik untereinander und mit ihren außermathematischen Anwendungen in Zusammenhang stellen. Sie erscheinen daher geeignet, bei der Auswahl, Organisation und Präsentation mathematischer Inhalte für den Unterricht zu orientieren und in der Folge die Mathematik für die Lernenden verständlicher zu machen.

Diese Arbeit gibt englischsprachigen Leserinnen und Lesern einen Überblick über entscheidende Stadien in der Entwicklung des Verständnisses solcher fundamentaler Ideen als didaktischer Kategorie in der deutschsprachigen mathematikdidaktischen Diskussion. Sie bettet diese Forschungsrichtung ein in den Kontext der im Rahmen dieses Themenhefts fokussierten Stoffdidaktik, zieht Vergleiche zum Konzept „Grundvorstellungen“ und stellt Verbindungen her zwischen diesen beiden Kategorien.

Schlüsselwörter Fundamentale Ideen · Didaktische Prinzipien ·

Geschichte der Mathematikdidaktik · Stoffdidaktik ·

Mathematikunterricht in den Sekundarstufen

\section{Preface}

There are at least three key tasks in mathematics education that most mathematics educators usually agree upon:

(1) Setting goals for student learning,

(2) Designing and enacting learning experiences for students, and

(3) Assessing student understanding and skills.

In addressing each of those challenges, curriculum designers and teachers generally focus on shaping a day-to-day regime of specific knowledge and skills they want students to master. But curriculum policy documents usually also articulate some fundamental ideas and reasoning processes that make a connection between the different areas of mathematics and its applications. Those interconnecting themes are ostensibly used to guide selection, organization and presentation of curriculum content. However, the effect of such considerations is not always apparent in the content of textbooks, tests or the everyday activities of mathematics classrooms.

In the German-speaking community of mathematics educators, the work of identifying and applying fundamental ideas has been (and still is) a common topic closely 
related to the research area this volume is dedicated to-subject matter didactics ("Stoffdidaktik"). Guidance by fundamental ideas has become an inherent part of the canon of didactical principles discussed within the German-speaking community, which may be credited to a large extent to its inclusion within Wittmann's widely read book Basic Questions of Mathematical Instruction (Wittmann 1974) ${ }^{1}$, in turn owing its inclusion to Bruner's seminal work The Process of Education $(1960,1977)$.

When speaking of guidance by fundamental ideas as a didactical principle, we must also concede that this principle - while widely spread and continually debated within the German-speaking community-has remained rather vague with respect to either the question what exactly constitutes a fundamental idea or what kind of guidance is to be expected from such a construct. As Jung (1978) stated, some of that vagueness may be necessary for fundamental ideas to be consensual among mathematics educators, applicable to rather broad areas of mathematical content and helpful in achieving the three previously mentioned tasks of mathematics education. However, it is also important to acknowledge that the perception of fundamental ideas and their didactic objectives are subjected to some important shifts in more general perceptions of mathematics education throughout the past 50 years.

Therefore, this article aims to provide the English-speaking reader with an overview of the intellectual-historical development of guidance by fundamental ideas as a didactical principle within German-speaking countries. For the purpose of better illustration, this overview will focus on four distinguishable stages within this development. It is also necessary to restrict this overview to the most frequently perceived conceptions of fundamental ideas or rather those assumed to be particularly characteristic for the different stages ${ }^{2}$. The section following this overview is dedicated to embedding the discussion of fundamental ideas within the larger context of this volume, that is subject matter didactics in general and relations to basic mental models ("Grundvorstellungen") as another key concept of this tradition also discussed within this volume. The article concludes with an outlook on more recent developments and pending issues regarding fundamental ideas as a category for mathematics education research and practice.

\section{First Stage: Predecessors and Prototypes (Klein and Whitehead)}

Linking the didactical principle of guidance by fundamental ideas back to the legacy of Felix Klein may in a stricter sense be considered an anachronism. This connection is claimed in respect to "educating functional thinking" as a guiding principle of the Meran reform, whereas "functional thinking" acts as a prototype of what will later on be called a "fundamental idea". Another connection lies in similarities between Meran reform and "New Math" as the background against which Klein and Bruner develop their approaches to mathematics education, respectively.

\footnotetext{
${ }^{1}$ In German: Grundfragen des Mathematikunterrichts. Any translations within this article have been made by the author unless stated otherwise.

${ }^{2}$ As such a judgment is subjected to personal preferences and bias, the reader may be referred to Heymann (2003, pp. 108-123) and Schweiger (2005) for other (English language) accounts on the matter at hand.
} 
Alfred N. Whitehead deliberates about the role of fundamental ideas for mathematics as part of a liberal education curriculum. However, his deliberations had no immediate effect on the mathematics curricula in German-speaking countries of that time. His thoughts about fundamental ideas are included in this paper because they are referenced a number of times much later after the discussion of Bruner.

\subsection{Felix Klein and the Meran Reform: Educating Functional Thinking as a Prototype of a Fundamental Idea}

The Meran reform is named after a symposium of the Association of German Natural and Medical Scientists in the city of Meran in 1905 and the syllabus that was formulated there. One of the main goals of Felix Klein and the Meran reformists was establishing "educating functional thinking" as a "special task" of mathematics as part of general education in schools 3 . What the Meran reform shares with "New Math" is that both can be considered an effort to close a growing gap between mathematics education in schools and mathematics as a research domain. Introducing differential calculus in the higher grades of mathematics education at high schools (Gymnasium) as an alternative to scientifically outmoded forms of algebraic analysis is the most visible and longer lasting consequence in this regard (cf. Biermann and Jahnke 2014).

But "educating functional thinking" was neither conceptually limited to this element nor was it limited to the sole goal of scientification. Functional thinking was originally understood in a rather broad sense, "relating cognitive processes, mathematical concepts and big ideas for general mathematics education" (Biehler and Peter-Koop 2008, p. 2). Not only was functional thinking and reasoning considered a bridge between mathematics in secondary education and mathematics at the university level, but also a unifying concept within school mathematics itself. Concentrating mathematics education on such topics, which act as exemplary specifications of functional thinking, was also considered a possible solution to the problem of "Stoffdruck" - the potential flooding of growingly detailed knowledge potentially caused by a simple pledge for "keeping pace" with the ever growing amount of scientific knowledge in mathematics. Within the Meran syllabus of 1905 functional thinking was intended to be introduced anticipatorily from the third year of Gymnasium onwards (Krüger 2000, p. 170). Both within arithmetic and geometry those anticipatory forms consisted of experimenting with and observing the effects of variations on parts of a geometric figure (or arithmetic term) on the figure (or term) as a whole. In this regard it can be considered a prototype for what would later on be outlined as one central aspect of the "operative principle" (cf. Krüger 2000, pp. 267-274).

Finally, functional thinking was also considered a concept linking mathematics and its applications. Throughout the nineteenth century the process of industrialization had a far-reaching impact on the work place and everyday life for a large part of the population. Mechanization of processes as a central feature of these changes is closely related to kinematic and functional understanding. Therefore, functional thinking could also be considered a way of overcoming mere formal justifications of mathematics as a general "school of proper thinking" by emphasizing its actual prag-

${ }^{3}$ Fostering spatial ability being the other "special task" mentioned in Gutzmer (1905). 
matic importance in science, economy and society. In this regard, the Meran reform coincides and integrates a broader movement of application-orientation, manifested e.g. in the integration of "classical topics of physics (e.g. law of falling bodies, trajectory parabola, oscillation of the pendulum)" (Krüger 2000, p. 135).

\subsection{Alfred N. Whitehead: Fundamental Ideas and the Role of Mathematics in Liberal Education}

Alfred N. Whitehead has dealt with the notion of guidance by fundamental ideas in at least three of his works: In both his educational essays The Mathematical Curriculum (Whitehead 1913/1967) and The Aims of Education (Whitehead 1916/1967) as well as in his first book about mathematics written for a larger public audience $A n$ Introduction to Mathematics (Whitehead 1911). In the later discussion about fundamental ideas in the German-speaking countries The Mathematical Curriculum is frequently chosen as one key reference point besides Bruner, while An Introduction to Mathematics has been mentioned only twice and at a relatively late stage ${ }^{4}$, although it presumably contains the clearest indications of what Whitehead thought to be fundamental ideas of mathematics.

What Whitehead is concerned with in both of the aforementioned essays is the danger of "mathematics, as practiced by the experts, $[\ldots]$ becoming isolated from other aspects of culture" (Heymann 2003, p. 112) and the notion that mathematics "in general opinion [...] is the very typical example of reconditeness" (Whitehead 1967, p. 78). Whitehead goes on to proclaim the "liability to reconditeness $[\ldots]$ the characteristic evil which is apt to destroy the utility of mathematics in liberal education" (ibid.). He even admits that mathematics "as it exists in the minds and in the books of students of mathematics is recondite. It proceeds by deducing innumerable special results from general ideas, each result more recondite than its preceding" (ibid.).

Whitehead claims the importance of distinguishing carefully between mathematics as a subject for all (in other words: its role as a subject in general or liberal education) and mathematics as a "subject of profound study" (ibid., p. 79, in other words: its role as an area of dedicated professional study within tertiary education). For the use of mathematics in liberal education, Whitehead proclaims that "a rigorous process of selection and adaption" is needed and mathematics instruction should "deal directly and simply with a few general ideas of far reaching importance" (ibid., p. 79). He argues that for "the purposes of education, mathematics constitutes of the relations of number, the relations of quantity, and the relations of space" (ibid., p. 80). However, Whitehead is well aware that there "is no royal road to learning through an airy path of brilliant generalisation" (ibid., p. 6) and "education is a patient process of the mastery of details, minute by minute, day by day" (ibid., p. 6). The difficulty in the apprehension of general ideas therefore is making "the pupil see the wood by means of the trees" (ibid., p. 6), i.e. providing students with convincing practical examples as "direct illustrations of the main ideas" (ibid., p. 81) so that they can finally recognize "that the preceding years of work have illustrated those relations of number, quantity

\footnotetext{
${ }^{4}$ In Schweiger (2005) and Schweiger (2010), although Schweiger's discussion of fundamental ideas dates back to Schweiger (1982).
} 
and space" (ibid. p. 80). He further emphasizes "that theoretical ideas should always find important applications within the pupil's curriculum" (ibid., p. 5).

Whitehead is also concerned about the disconnectedness of school subjects which "kills the vitality of our modern curriculum" (ibid., p. 6). Taking the teaching of algebra as an example, Whitehead argues that there is no reason to teach e.g. the solution of quadratic equations unless it fits "a connected curriculum" wherein quadratic equations can be understood as a special manifestation of algebra as a more general "intellectual instrument which has been created for rendering clear the quantitative aspects of the world" (ibid. p. 7). Likewise he argues that "Geometry and Geometrical Drawing must be extended beyond the mere circle of geometrical ideas. In an industrial neighbourhood, machinery and workplace practice form the appropriate extension" (ibid., p. 10).

Whitehead draws a clear distinction between mathematics as an area of professional study and mathematics for the purpose of liberal education. Additionally, he draws attention to the fact that only such ideas would facilitate mathematics education, which give an immediate sense of urge and meaningfulness to students. This appears to be somewhat forward-looking when compared to early interpretations of Bruner's calls for "guidance by fundamental ideas" against the background of "New Math" about 50 years later.

\section{Second Stage: Mathematical Structures as Ideas Guiding Curriculum Development against the Background of "New Math" (Jerome S. Bruner)}

It is next to impossible to write a comprehensive summary of Bruner's The Process of Education and the impact it had either on the "New Math" movement in general or on "Neue Mathematik" as its counterpart in Germany and Austria when one can only dedicate a few pages to this topic. I consider it essential to acknowledge that "guidance by fundamental ideas" does not really evolve as a didactical principle in German-speaking countries until two of the most prominent features of early interpretations of Bruner within the "New Math" paradigm are challenged:

- Firstly, the assertion that "mathematical structures" which are fruitful and important for research in mathematics can automatically act as fundamental ideas guiding the mathematical curriculum and the activities of students from the outset and throughout their learning processes.

- Secondly, and even more essential, the assumption that mathematics as a science has a clear consensus on what those fundamental structures are. Namely, those structures emphasized in structural mathematics as they were put forward by the Bourbaki group.

For all intents and purposes, the notion of "the importance of structure" was far more relevant for the shape and form of "New Math" than the notion of "guidance by fundamental ideas". In The Process of Education both notions are at least deeply connected - one could even consider Bruner's use of the phrases "fundamental idea" and "basic structure" as ultimately interchangeable. 
The most commonly cited excerption from The Process of Education is likely its "bold hypothesis" that "any subject can be taught effectively in some intellectually honest form to any child at any stage of development" (Bruner 1977, p. 33). This hypothesis is grounded upon Bruner's strong belief "that intellectual activity anywhere is the same, whether at the frontier of knowledge or in a third-grade classroom. What a scientist does at his desk or in his laboratory [...] are of the same order as what anybody else does when he is engaged in like activities - if he is to achieve understanding. The difference is in degree, not in kind." (ibid., p. 14). Bruner was convinced "that the academic disciplines or topics have a tendency to arouse curiosity in human beings in general, including children" and therefore opposed the view that educators should "make subjects or topics more accessible or palatable by presenting them in real-life settings of children's daily experience. Instead, subjects and topics must be presented according to the structures of the academic disciplines which are the essence and reflection of accumulated human curiosity" (Takaya 2008, p. 7).

Bruner gives four arguments for the importance of structure for the learning process:

1. Understanding the "fundamentals makes a subject more comprehensible" (Bruner 1977, p. 23) as otherwise presumably special and isolated phenomena can now be understood as special cases of a more general phenomenon.

2. Unless detailed knowledge "is placed into a structured pattern, it is rapidly forgotten" (ibid., p. 24).

3. Fundamental ideas and principles are a necessity for "transfer of training" because to "understand something as a specific instance of a more general case [...] is to have learned not only a specific thing but also a model for understanding other things like it that one may encounter" (ibid., p. 25).

4. Through emphasizing fundamental structures and principles "one is able to narrow the gap between 'advanced' knowledge and 'elementary' knowledge” (ibid., p. 26).

While elaborating on the importance of structure for the learning of a subject Bruner also speaks of "basic ideas that lie at the heart of all science and mathematics" (ibid., p. 12), "mastery of the fundamental ideas of a field" (ibid., p. 20), "understanding of the fundamental structure of whatever subjects we choose to teach" (ibid., p. 11), and "designing curricula in a way that reflects the basic structure of a field of knowledge" (ibid., p. 32). The inconsistent use of either one of the adjectives "basic" or "fundamental" as well as either one of the terms "idea" or "structure" makes it doubtful that Bruner intended to define a new concept "fundamental idea".

Bruner does not fail to mention the importance of intuition and discovery learning in acquiring fundamental ideas, structures and principles of a subject. His famous "spiral curriculum" calls for "an emphasis upon the intuitive grasp of ideas" in early learning and for revisiting these ideas "repeatedly, building upon them until the student has grasped the full formal apparatus that goes with them." (ibid., p. 13). While this "spiral curriculum" advocates research into ways of teaching that allow for such an intuitive grasp of fundamental ideas and principles, the connection between mathematics learning in schools and mathematics as a research domain is otherwise a rather direct one: What ideas, principles and structures are to be regarded "fundamen- 
tal" is a question that according to Bruner is up to the "most able scholars and scientists" (ibid., p. 19) to decide reflecting their own scientific practice in mathematics.

Against the backdrop of "New Math" the answers given consisted of fundamental concepts and principles derived more or less directly from the hierarchy of logical structures of pure modern mathematics along the lines of Bourbaki, e.g. "basic conceptions such as composition/order/topology or set/structure/mapping” (Tietze 1994, p. 48). The Bourbaki group had been rather successful in showing that "concepts and principles of the major branches of mathematics can, in some sense, be derived logically from a small set of primitive assumptions and structures" (Fey 1994, p. 17). If one is convinced that mathematical knowledge is "structured in an optimum way in the modern sciences" (Heymann 2003, p. 114) one is easily led to the conclusion that the "primary task of schooling is to transform the 'structure of the disciplines' into the cognitive structure of the learner" (ibid.). It is also important to take into account that "the process of education" is not restricted to examples from mathematics but rather discusses the importance of structure based on examples from both sciences and humanities, where 'structure' does not per se refer to an equally specific denotation as it does in structural mathematics. It is therefore questionable whether Bruner himself intended such a narrow interpretation.

\section{Third Stage: Overcoming "New Math" through Genuinely Researching Fundamental Ideas (Schreiber, Schweiger, Tietze and Others)}

If one takes "New Math" and its emphasis on logical structures in school mathematics for a realization of Bruner's notion of "guidance by fundamental ideas", there is little doubt that with hindsight this realization can be regarded a failure.

What was contested early in the discussion was the identification of fundamental ideas with "basic structures" along the lines of Bourbaki. For example, Freudenthal strongly opposed identifying basic conceptions such as set, structure and mapping with fundamental ideas for mathematics in school. He argues that the original meaning of such "structures of a discipline" merely consists of codifying "systematically (and in the case of mathematics this means deductively) the state of that science at a given moment and, for that matter, of a science that is not even the subject of the instruction envisaged" (Freudenthal 2002, p. 28). Such a purpose requires a hierarchy of structures "from poorer to richer" (ibid.) which Freudenthal deemed potentially harmful when imitated within curriculum design:

Poor structures are utterly abstract as is evident from the poorest of all, the structure-less set. Didactically one cannot come to grips with it, or it should be by concretising, by filling out the abstract form, and in practice this is done by creating artificial, and often even false concretisations. In genuine mathematics, sets as well as all of these structures serve goals; they are because they are operational. At the level where science structure curricula start, however, there is nothing mathematical one can do with sets. So, as a curriculum designer, one arbitrarily invents things to do with sets, which have nothing to do with the need for sets in mathematics (Freudenthal 2002, pp. 28/29). 
Wittenberg $(1963$, p. 55) voiced equal criticism towards the use of the terminology of structural modern mathematics denouncing it a mere "aping" of a language whose peculiarities cannot be valued when applied to the rather restricted range of mathematical topics one can usually cover in school. Fischer (1985, p. 62) argues in the same vein as Freudenthal: Basic structures along the lines of Bourbaki serve specific functions in university mathematics. When simply appending such conceptions to school mathematics they tend to lose their meaningfulness and social-communicative character. Both Lenné (1969) and Damerow (1977) did extensive research into the influence "New Math" had on mathematics education in Germany. Lenné (1969, pp. 95-103) already noted that the realization of "New Math" within the Nuremburg syllabus of 1965 did not deliver on the promise of rethinking, reducing and restructuring the increasingly overwhelming amount of mathematical subject matter potentially to be taught in school. On the contrary, he found that emphasizing the "structure of the discipline" more often than not meant the inclusion and addition of new concepts and with them new contexts and topics, in which those concepts could prove themselves useful, as they had little to no meaning in more traditional topics. Analysing the Standing Conference of Ministers of Education and Cultural Affairs' 1968 curriculum framework, Damerow (1977, pp. 225 f) found that the newly introduced and rather abstract concepts were often included within topics that did not provide a sound basis and lacked meaningful applications. This repeatedly resulted in a mishmash of traditional approaches and modern approaches with some concessions regarding age appropriateness.

I consider the generally accepted failure of "New Math" the necessary turning point for the formulation of fundamental ideas as a genuine research problem of subject matter didactics. In acknowledging that mathematicians had no consensus on "fundamental ideas" appropriate for curriculum design, identifying such ideas became a genuine research goal of subject matter didactics. The years between the early 1970s and the late 1980s are the formative years for this research problem. Within this timeframe three essential conceptions of "fundamental ideas" and their role in curriculum design and classroom practice are worked out partly independent of each other while unified by both recalling Bruner's views on the role of fundamental ideas and by rejecting or modifying earlier interpretations of Bruner at least in some respect. The crucial lesson learned from the failure of "New Math" within these conceptions was beginning to embrace Thom's stance that "whether one wishes it or not, all mathematical pedagogy, even if scarcely coherent, rests on a philosophy of mathematics" (Thom 1973, p. 204), i.e. those conceptions are incrementally taking better account of and concerning themselves with genuinely didactical categorizations as a perquisite for identifying fundamental ideas.

\subsection{Universal and Central Ideas (Schreiber)}

Alfred Schreiber's conception of universal and central ideas already defines itself in rejecting the proposed designation "fundamental ideas". He finds such a designation misleading since it evokes a sense of "fundamentalism". But the mathematical ideas he is concerned with are in no way related to questions about "fundamentals" along the lines of the Bourbaki group and their involvement with the foundations of math- 
ematics. Schreiber follows Freudenthal in arguing that universal ideas should not focus on mathematics as a finished product but rather on mathematical processes and/ or processes of mathematization. He thinks of universal ideas as general schemes, which are used in such processes "which set these processes into motion and keep them going” (Schreiber 1979, p. 166). If we cast our minds back to Bruner's claim of the equivalence of activities both students and researchers at their respective "frontiers" partake in, we might argue that by emphasizing processual aspects of (yet) unfinished mathematics Schreiber tries to correct one of the misunderstandings of "New Math" and more directly relates to Bruner's initial intentions.

Universal ideas according to Schreiber should also help to discover the archetypical and pretheoretical roots of mathematical concepts and procedures within the realm of common sense. In this regard he sees a considerable need for research as he deems forgetting and/or eliminating any traces of common sense reasoning within mathematics as something the science itself generally favors (cf. Schreiber 1983, p. 67). While within "New Math" the main justification for reorganizing the curriculum according to "fundamental ideas" or "the structure of the discipline" was the importance these ideas and structures had within mathematics as a scientific domain and may therefore be summarized as "legitimization through scientification". Schreiber rejects such a narrow focus and directly refers to Whiteheads argumentation: Universal ideas should be "universal" in the sense that they should have a broad importance for everyday life and also help to provide a better understanding of mathematics in the context of scientific activities in general (cf. ibid. p. 67).

Schreiber (1979) proposes algorithm, exhaustion, optimality, function, characterization as potential candidates for universal ideas. In Schreiber (1983) his (provisional) catalogue of ideas has already grown to a number of 15 ideas grouped within three categories: procedures (exhaustion, iteration, reduction, transformation/ mapping and algorithm), properties (quantity, continuity, optimality, invariance and infiniteness) and components of concept formation processes (ideation, abstraction, representation, space and unit). Schreiber (1983) also specifies three criteria for the "universality" of the ideas in question:

1. Width (logical generality),

2. Richness (broad applicability and relevance in different areas of mathematics)

3. Sense (anchoring within the realm of common sense, relevance and meaning in real life situations) (Schreiber 1983, p. 69).

Schreiber is well aware that both this conceptualization of universality and his catalogue of universal ideas imply concepts and procedures of a rather general nature. $\mathrm{He}$ is therefore very careful in stating that these universal ideas are primarily to be considered components of meta-knowledge aimed at mathematics teachers and curriculum designers, not to be confused with mathematical content directly aimed at students.

Additionally, Schreiber (1979, p. 167) already mentions the idea of identifying central ideas as less general embodiments of universal ideas specific to particular areas of mathematics. In fact, he regards the identification of area-specific central ideas as one of five key issues where further research about universal ideas is necessary. Central ideas and their relation to universal ideas is a topic further elabo- 
rated upon in Bender and Schreiber $(1985)^{5}$ regarding geometry as an example. The predominant role of central ideas for learning mathematics is stressed here, i.e. the authors are claiming that "learners may reach an understanding of universal ideas first and foremost through reaching an understanding of central ideas (of specific areas of mathematics)" (Bender and Schreiber 1985, pp. 199/200). Bender and Schreiber (1985) discuss rigid body, homogeneity, measurement and fitting of forms as central ideas more specific to geometry while also discussing the importance of more universal ideas such as exhaustion and optimization. Within the framework of operative concept formation Bender and Schreiber (1985) conceive the didactical principle of guidance by universal and central ideas in close relation to other didactical principles such as the genetic principle (mathematical courses should take into account and integrate aspects of both the psychological development of children and the historical development of mathematics), the teleological principle (mathematical courses should explicitly be aimed at specific goals namely such goals which give learners a sense of purpose and meaning) and the principle of pragmatic ordering (each step in a course has to be taken at an appropriate point, i.e. nothing precedes it or is taken for granted, which can only be achieved by taking this step).

While Schreiber (1979, p. 167) included research into the use of universal and central ideas in classroom practice as another key issue of further research, his considerations never quite reached that level of concrete implementation let alone systematic empirical study. Moreover, it is well justified to consider Bender \& Schreiber's Operative Genese der Geometrie (transl. to: Operative Genesis of Geometry) (1985) a more pronounced example of research into the consequence of guidance by fundamental ideas for curricular design, but for a large part the book remains on a conceptual level as far as actual classroom practice is concerned. Additionally, both Bender and Schreiber (1980) and Bender and Schreiber (1985) contain some example lessons at least partly held by the authors. These lessons tend to illustrate the more comprehensive principle of operative concept formation, not the principle of guidance by universal or central ideas by itself. However, operative concept formation is both limited to geometry in scope and explicitly rests on a very specific philosophy of mathematics, namely Hugo Dingler's operationism ${ }^{6}$, which has not been adopted widely within mathematics education research ${ }^{7}$.

Schreiber republished his collected works on concept formation in 2011, including his papers on universal and central ideas along with a rather disenchanting postscript on this topic. He concludes that there is little to no effect of didactical considerations about fundamental ideas on actual classroom practice as of yet. He argues that nowadays neither educational zeitgeist nor prevalent practical problems of teachers would leave much room to contemplate about fundamental ideas of mathematics. He also admits that his initial hopes regarding central or universal ideas acting as an agent of concept formation were widely disappointed, retrospectively. In closing he suggests

${ }^{5}$ Following Bender (1978) and Bender (1983); for an English language overview see also Bender and Schreiber (1980).

${ }^{6}$ For a brief overview of Dingler's philosophy see cf. Wolters (1988).

${ }^{7}$ Schreiber $(2011$, p. 153) also admits his own attempts at resting geometry instruction upon this philosophy proved rather difficult and were of limited success at best. 
it may be more helpful to think of fundamental ideas as ex post heuristics of concept formation, which learners should not be confronted with until a certain amount of knowledge has been achieved and may serve as a basis for meaningful retrospection (cf. Schreiber 2011, pp. 91/92).

\subsection{Fundamental Ideas (Schweiger)}

Fritz Schweiger developed another conception of fundamental ideas roughly at the same time as Schreiber. While retrospectively it may be considered an extension or modification of Schreiber's conception (especially regarding the list of criteria for identifying such ideas), by his own account Schweiger wrote his first article on fundamental ideas (Schweiger 1982) largely unaware of Schreiber's work. In Schweiger (1992) he cites Bruner (1960), Fischer (1976) and Freudenthal (1973) as his initial sources of inspiration. Schweiger (1992) on the other hand gives the first comprehensive survey on the current state of research and the development of fundamental ideas as a field of mathematics education research, also marking the pivotal point of theoretical discussion on this topic at least within this phase of the discussion.

The core and most influential part of Schweiger's conception of fundamental ideas is its catalogue of criteria for identifying fundamental ideas rather than its collection of proposed fundamental ideas. The latter again proclaimed solely prospective and therefore ever changing and growing, the former remaining largely unchanged up until Schweiger (2005). Schweiger (by his own account preliminarily) defines a fundamental idea as follows:

A fundamental idea is a bundle of actions, strategies and techniques, which

(1) can be identified within the historical development of mathematics,

(2) appears viable in structuring curricular designs vertically,

(3) is deemed appropriate in both getting an idea of what mathematics is about and fostering conversations about mathematics,

(4) helps making mathematics instruction both more flexible and more accessible,

(5) has a corresponding linguistic or operational archetype within the realm of everyday language and activities. (Schweiger 1992, p. 207)

While criterion (5) directly mirrors the "sense" criterion proposed by Schreiber, both conceptions differ regarding the conceptualization of the broadness of a mathematical idea that is to be considered universal or fundamental. Schweiger's definition does neither explicitly require the "width" (logical universality) nor the "richness" (transcending the borders of traditional branches of mathematics) of Schreiber's universal ideas. Schweiger draws more attention to the diachronic, vertical dimension in requiring fundamental ideas to both recur in the historical development of mathematics (1) and on different levels of the mathematical curriculum (2). Compared to Schreiber's criteria, criteria (1) to (3) of Schweiger (1992) are formulated more directly bearing in mind the potential didactical functions of fundamental ideas. Schwill (1993) explicitly regards them as normative criteria, a view adopted in Schweiger (2005). Schweiger's catalogue of criteria may lack Schreiber's "width" criterion, but the fundamental ideas he proposes are not less general per se- his earliest catalogue, 
e.g. consists of linearization, bifurcation, similarity, stability, independence of interferences, canonical forms, typical behaviour and the power of formalization.

Schweiger's criteria for identifying fundamental ideas have been widely recognized and adopted (with some specific omissions, additions and modifications), e.g. by Schupp (1984), Humenberger and Reichel (1995), Führer (1997) and Peschek (2005). Schwill (1993) is a special case regarding the explicit integration of Schreiber's "richness" criterion ["fundamental ideas recur in different parts of mathematics (horizontal dimension)"], a differentiation between descriptive and normative criteria as well as to the effect of applying fundamental ideas to informatics education rather than mathematics education. Schwill (1993) also subdivides Schweiger's criterion (2) into a descriptive part ["fundamental ideas recur at different levels (vertical dimensions)"] and a normative part ["fundamental ideas should help to design curricula"].

Schweiger does not differentiate distinct levels of fundamental ideas similar to Schreiber's distinction between universal and central ideas. However, Schweiger (1992) includes the notion of a hierarchy of fundamental ideas which may be summarized as follows: All sciences develop and share some universal ideas in general which may be interpreted as a continuation of everyday activities and thinking. Each science also has some characteristic ideas separating one from another. Accordingly, each specific area of mathematics both shares some ideas with every other area of mathematics and has some ideas characteristic for itself. All of these ideas are potentially relevant as fundamental ideas for mathematics instruction. Therefore, educational research should try to construct semantic nets between these ideas and to design curricula which help students to achieve a continually broadening understanding of more and more universal ideas. However, he is well aware that such an undertaking might at the lowest level result in catalogues so broad and close meshed they simply duplicate "the table of contents of any relevant textbook" (ibid., p. 209).

While both Schweiger (1982) and Schreiber (1983) embraced the idea of developing a canon of fundamental ideas as a key issue of research into fundamental ideas, Schweiger (1992) already considers the goal of canonization unattainable, at least as far as mathematics as a whole is concerned. Thus, it is hardly surprising that research regarding fundamental ideas during the third stage shifted considerably towards research regarding central ideas of specific areas of (school) mathematics and to research regarding specific ideas prospectively assumed fundamental, i.e. to such lines of research, where either a consensus was easier to achieve or the lack of consensus easier to tolerate because questions about the essence or nature of mathematics in general could partially be set aside.

\subsection{Central Concepts, Subject-Specific Strategies and Patterns of Mathematization (Tietze, Klika \& Wolpers)}

The third influential conception of fundamental ideas was originally developed by Tietze (1979) and it takes a more pragmatic and inductive approach to fundamental ideas. The publication Tietze (1979) is devoted to fundamental ideas of linear algebra and analytic geometry, while in Tietze et al. (1982) he and his co-authors extend their conception to mathematics instruction in the upper secondary school years in general. 
The core of this conception is a distinction between three different types of fundamental ideas: central concepts, subject-specific strategies and patterns of mathematization. To put central concepts of scientific mathematics on the same level as fundamental ideas was a rather risky undertaking regarding the generally accepted failure of new math in this regard. Tietze et al. (1997, p. 47) are therefore keen to emphasize that only such concepts should be assumed fundamental, which "retain their value of organizing a broad range of phenomena within school mathematics and therefore can inspire mathematics instruction". Tietze (1994, p. 49) also stresses that "central concepts of a subject matter depend on the perspective from which one looks at it. If one takes Bourbaki's perspective on linear algebra, then vector space, linear mapping, scalar product, and Steinitz exchange theorem are central. If one looks at it from the angle of 'linear algebra and its applications' then linear equation and Gaussian algorithm are fundamental".

What is not contested here, is that central concepts of a developed science may act as fundamental ideas for mathematics teaching and learning - a prerequisite neither Freudenthal nor Schreiber took for granted drawing more attention to the process of mathematization. This processual aspect is on the other hand embraced within Tietze, Klika \& Wolper's conception by including subject-specific strategies as more informal "strategies of problem solving or strategies of proving, identifying connections and concept formation in particular" (Tietze et al. 1997, p. 41). Similarly, the inclusion of patterns of mathematization may be understood as a countermeasure to early interpretations of fundamental ideas which tended to reduce them to the basic structures of pure mathematics, whereas patterns of mathematization refer to applied mathematics or applications of mathematics in general.

Both the distinction of central concepts, subject-specific strategies and patterns of mathematization and the attempt to identify fundamental ideas of mathematics inductively by starting with the ideas of specific areas of mathematics may be seen as a double-edged sword: Tietze (1994) both justifies the distinction and the inductive approach with the otherwise too general nature and the lack of influence that universal ideas along the lines of Schreiber have on mathematical instruction. In return, Tietze, Klika \& Wolpers diverge from the notion of set of a few fundamental ideas that lie at the heart of all mathematics, especially by including central concepts of mathematical topics. In fact, it is no exaggeration to state that the catalogue of ideas Tietze et al. (1982) compiled shares a very close resemblance with the table of contents of any (good) textbook. It is also up for debate whether including central concepts by themselves as fundamental ideas does any service to this construct. Schweiger (1992) argues that for a concept to be central or act as an idea it almost inevitably has to either act as a subject-specific strategy or as an important pattern of mathematization or even both. Otherwise, there is little specific guidance such a concept can have for mathematics instruction apart from covering the concept itself. 


\section{Fourth Stage: Fundamental Ideas, Mathematical Literacy and General Education (Heymann, PISA, National Educational Standards)}

Admitting the need for research into the subject matter to identify fundamental ideas and admitting that what is considered a fundamental idea depends on the perception of what is essential in mathematics (an implicit or explicit philosophy of mathematics) was proclaimed the major shift from the second to the third phase of the discussion about fundamental ideas. This aspect continues to gain significance in the fourth phase of this development and it takes a specific spin regarding the perception of what is essential in mathematics as far as mathematics instruction is concerned. In this phase the question what mathematical ideas should be considered fundamental for mathematics instruction is explicitly related to larger frameworks of mathematics education, especially the long-standing German tradition of general education as reinterpreted by Heymann $(1996,2003)$ and the debate about mathematical literacy along the lines of the PISA framework. It will also be of interest that by including leading ideas into the newly introduced National Educational Standards for Mathematics in Grades 5-10 (KMK 2004) some kind of consensus on canonical fundamental ideas has been reached by decree and what repercussions this implies.

\subsection{Main Ideas and Cultural Competence Within Heymann's Framework for General Education}

Heymann's book Allgemeinbildung und Mathematikunterricht $(1996)^{8}$ led to an intense debate on the future of mathematics instruction. Its goals and relevance for society, which was somewhat intensified by the coinciding publication of the results of the TIMS Study, generally deemed unsatisfactory regarding the performance of German students and therefore another reason to scrutinize the current state of affairs in mathematics instruction. While Heymann's approach is rooted in the long-standing tradition of general education ("Bildung") within humanistic pedagogy", he sets out to establish a more pragmatic understanding of this rather broad, sometimes rather emphatic category by clarifying "the idea of general education as a basic education for all members of a society and to concretize this idea with respect to teaching practice" (Heymann 2003, p. 3). He considers such a broader frame of reference increasingly important for mathematics education because "conventional mathematics instruction in schools does justice neither to foreseeable societal demands nor to the individual needs and qualification interests of a majority of adolescents" (ibid., p. 2), both of which are traditional objectives of general education.

The core of Heymann's framework of general education consists of "seven distinguishable, interconnected objectives of a school system aiming at general education" (ibid., p. 5) which are then applied to mathematics as a subject in school by

\footnotetext{
${ }^{8}$ An abridged English edition was published in 2003 as Why teach Mathematics? A Focus on General Education.

${ }^{9}$ Unfortunately, exactly the chapter on this tradition is omitted in the English edition, for an overview cf. Klafki (2000).
} 
identifying "deficits of the current widespread form of mathematics instruction and to determine which innovations [...] are necessary in order to do more justice to the claim of realizing general education" (ibid.). To this end, "guidance by fundamental ideas" is one of the "existing concepts of mathematics teaching" Heymann assesses anew and modifies "in the light of the idea of general education and personal development" (ibid.) in a chapter dedicated to the objective "cultural competence" (ibid., pp. 105-130).

I have to confine myself to a very brief summary of what cultural competence is about according to Heymann, who summarizes the objective as follows:

Schools should enable adolescents to attain a reflective cultural identity:

to experience themselves as part of the culture in which they grow to maturity

-with its favourable and unfavourable aspects;

to recognize common elements within their own culture, apart from its breakdown into disparate subcultures;

to accept the otherness of foreign cultures as an equally justified form of human existence. (ibid., p. 30).

Heymann considers the traditional subdivision of education into different school subjects with their close relations to corresponding scientific disciplines ambivalent as far as the objective of cultural competence is concerned. It may be justifiable to "legitimize subjects taught at school and, as far as such an affiliation is postulated, the corresponding academic disciplines as avenues of access to the cultural diversity of the world around us". However, such arguments are prone to "promote a specialist one-sidedness", i.e. "the detached coexistence of various individual subjects does not produce cultural competence" (ibid., pp. 33/34). As a countermeasure Heymann proposes main ideas "which can be used to bridge the gap between the subject and the culture external to it, which clearly demonstrate what significance the subject (or the corresponding academic discipline) has for cultural development, how it is interwoven with such development, and how it is connected to everyday life in society" (ibid.).

Once Heymann turns to the subject of mathematics instruction in particular, the notion of orienting to main ideas becomes his main topic in conceptualizing cultural competence. When assessing the discussion about fundamental ideas in mathematics education, he goes into greater detail regarding the conceptions of Whitehead and Bruner, while more recent conceptions from the German-speaking community are only briefly discussed in the context of a synopsis of catalogues of fundamental ideas he uses as a sort of "excavation site" (ibid., p 120) for his own catalogue. Heymann also chooses some unique points of reference not usually mentioned in other conceptions of fundamental ideas, i.e. he draws much inspiration from Bishop's (1988) approach to transcultural basic mathematical activities and also dedicates a section to Wittenberg's (1963) fundamental intellectual experiences.

Setting aside specific differences and priorities, Heymann (2003, p. 118) gathers three objectives that are mutually agreed upon among different proponents of fundamental ideas: 
(1) overcoming the dissolution of mathematics education "into a simple collection of separate, individual activities and topics" and helping students to "assign a more generalized meaning to their activities in the mathematics classroom";

(2) fostering the acquisition of "an appropriate image of mathematics" through recognizing the "structure of the discipline" as a means for interconnecting "often isolated individual topics" and "clarifying the specific characteristics of the discipline and illuminating the distinctive features of mathematical thought";

(3) allowing "the learners to perceive how the mathematics taught in school is connected to their other experiences of the world and to their own thinking", in contrast to (2) not so much emphasizing "the 'distinctive features' of mathematics, but $[\ldots]$ its meaning and function for recognizing and forming the world around us" and "how mathematics is also relevant outside the scope of mathematical specialization".

Heymann goes on to assert objective (3) to be "especially significant" in promoting cultural competence. This objective played a prominent role in both the Meran reform and Whiteheads considerations, was largely absent within the "New Math" interpretation of Bruner and then again more prominently present in the concepts of the third stage of development discussed above. It is worth noting that the predominant role Heymann assesses in this regard is a departure from earlier conceptions. In fact, Heymann ends up with a catalogue of considerably fewer general ideas (number, measuring, structuring space, functional relationship, algorithm, mathematical modelling) when compared to those of Schreiber and Schweiger. The prevailing focus on ideas which designate "interfaces between mathematics and culture as a whole" (ibid., p. 109) also becomes immediately apparent. That is not to say that Heymann sees objective (3) as the sole criterion for identifying main ideas. Regarding his catalogue he proclaims that each idea he chose had to be included in at least one of the earlier catalogues, should be present at different levels of doing mathematics and none of them should "exclusively represent a particular mathematical topic" (ibid., p. 123). But the objective of orienting mathematics towards these ideas is promoting cultural competence and apart from algorithm the descriptions of his main ideas strongly emphasize real-world applications and interconnections with the culture surrounding mathematics. While none of his ideas may strictly represent only a single mathematical topic, many of the ideas he mentions relate predominantly to specific traditional strands of school mathematics (number: arithmetic; measurement \& structuring space: geometry; functional reasoning: algebra and functions). To this respect one might argue that Heymann's account of main ideas is an attempt to establish a more pragmatic understanding of fundamental ideas both in scope (in downplaying the role of the "structure of the discipline" or mathematics as a scientific discipline in general) and in focus (in more directly linking fundamental ideas to the purpose of connecting mathematics to everyday life and therefore making them more immediately useful for students). 


\subsection{Big Ideas and Leading Ideas: From PISA to the Introduction of National Educational Standards for Mathematics in Germany}

Another potential way to describe the fourth stage's new spin in the perception of fundamental ideas can be achieved by using a distinction proposed by Prediger (2014): While at the second and third phase fundamental ideas often focus on mathematical concepts, procedures and activities themselves, conceptions at the fourth stage of this development tend to focus on "perspectives of the discipline on reality" (Prediger 2014 , p. 388) mathematics provides, therefore conceptualizing fundamental ideas as "interfaces between mathematics and reality" (ibid., p. 387). This is not only true for Heymann but even more so for both the big (or overarching) ideas within the PISA framework and the leading ideas as used within the National Educational Standards for Mathematics in Grades 5-10 introduced in 2003 (KMK 2004).

Both PISA and educational standards are first and foremost frameworks for assessing student knowledge and/or competencies, which is a rather big departure from use cases of fundamental ideas up until this point, i.e. other conceptions were focussed on the input side of educational processes (designing curricular processes) rather than its output side (assessing outcomes of such processes). This change of focus has some important repercussions on the conception of fundamental ideas and their role in mathematics instruction.

Firstly, mathematical literacy defined as "the capacity to identify, to understand, and to engage in mathematics and make well-founded judgements about the role that mathematics plays, as needed for an individual's current and future private life, occupational life, social life with peers and relatives, and life as a constructive, concerned, and reflective citizen" (OECD 2000, p. 50) even more clearly as Heymann's framework in general or his thoughts about cultural competence in particular is confined to mathematics instruction providing a set of relevant perspectives on reality. This is also apparent if one looks at the set of four big ideas itself:

- space and shape,

- change and relationships,

- quantity,

- uncertainty.

This aspect is further emphasized when these big ideas are introduced as an alternative to the traditional way of subdividing school mathematics into different well-established content strands (arithmetic, geometry, algebra, calculus etc.). One argument given for choosing this alternative is that to stay "relevant mathematics must reflect the complex patterns in the world around us" (ibid., p. 53). The four big ideas are then defined as distinguishable areas of phenomena, in which mathematics helps to observe and study such complex patterns.

Secondly, in establishing big ideas as an alternative for curricular strands the PISA framework to some extent downplays the importance of interconnectedness both of different ideas with each other and of different topics related to one idea across different content strands. When compared to established content strands, these big ideas may lead to somewhat different partitions of the mathematical curriculum. But in the end there can be little doubt that the big ideas are designations for such parti- 
tions. This is admitted partially in stating that a selection of ideas was chosen, which "offers sufficient variety and depth to reveal the essentials of mathematics and [...] relates to the traditional curricular strands" (ibid., p. 53). The PISA 2003 framework renames "big ideas" to "overarching ideas" and even more modestly states that with the (unchanged) set of four ideas "mathematical content is organized in a sufficient number of areas to ensure spread across the curriculum, but at the same time a number small enough to avoid a too fine division" (OECD 2003, p. 35). Interestingly enough, the PISA 2012 framework while choosing the same four content areas and providing the same overall rationale for doing so, has done away with the designation "big ideas" or "overarching ideas" altogether, simply speaking of four "broad areas of content" (OECD 2013, p. 32).

Within the German-speaking community of mathematics education research the big ideas of PISA were initially not considered as a part of the tradition of fundamental ideas along the lines of Bruner and the ongoing discussion within German-speaking countries - as a matter of fact, the different versions of the international PISA framework do not refer to Bruner or any other conception of fundamental ideas discussed above. The German PISA Mathematics Expert Group explicitly draws a distinction between fundamental ideas as "relatively general mathematical ways of thinking [.] as means for grouping content" and big ideas predominantly designating "connections to contextually defined areas of phenomena" (Neubrand et al. 2001, p. 11). Again, it is not contested that these big ideas are ultimately a functional equivalent to traditional strands of curricula, but it is argued that the particular big ideas chosen in PISA would at least call for some rethinking of curricular priorities in Germany, e.g. regarding the minor role of spatial geometry within the traditional curriculum. Winter (n. d.) argues that "big ideas" in PISA "to my account are not fundamental ideas, they rather designate fields of activity [...], or better yet, regions of sources for mathematical activities". Then again, Baptist and Winter (2001, pp. 59/60) argue strongly in favour of the understanding of "big ideas" within the PISA framework as a means for selecting content related goals appropriate for general education.

When the German National Educational Standards for Mathematics in Grades 5-10 were put into effect by the Standing Conference of the Ministers of Education and Cultural Affairs in late 2003, leading ideas were introduced and both their main purpose as a new way of designating particular content areas and their stronger connection to contextually defined areas of phenomena were in large parts directly adopted from PISA. The set of leading ideas (number, measurement, space and shape, functional relationship, data and chance) bears both a close resemblance to the main ideas of Heymann and the big ideas of PISA. The introduction of standards and a national regime of assessment of these standards along with the specific understanding of general education in mathematics (which again draws some inspiration from the understanding of mathematical literacy in PISA) has not been a frictionless process and continues to draw some opposition. Yet, to my understanding, the leading ideas themselves have not been drawing much attention or criticism for that matter. We have to take into account that the main purpose of the educational standards is to "determine which competencies students should have acquired in a subject area by a certain grade" (KMK 2004, p. 3). Each leading idea (e.g. measurement), is therefore accompanied by a set of about ten discernible competencies (e.g. "students are able to 
calculate the area and circumference of the rectangle, the triangle, the circle and compounds of these figures" ibid. p. 10). While one can surely understand the calculation of the area of a circle as a problem of measurement, for the students to pass the test it is essential to correctly calculate the area, not to think about how this calculation is related to measurement in geometry or in general. If we would on the other hand e.g. require teachers to introduce the problem of the calculation of the area as a problem of measurement and to relate it to similar measurement problems and strategies students have already met, we may be in line with the notion of orienting to fundamental ideas along the lines of the conceptions of the third phase. But educational standards are standards for outcome rather than standards for ways of teaching and learning, at least technically they do not justify such requirements.

Bluntly said, the little opposition main ideas have met may partly be attributed to the fact that the potential for innovation in orienting towards these main ideas is effectively rather small. The leading ideas mainly operate as designations for areas of contexts and contents. For that matter they bundle context and contents which are closely related to already well-established topics of mathematics instruction and which were already bundled and separated in similar ways according to the subdivision implied by more traditional content strands. Because the standards are first and foremost standards for assessment and evaluation, they also do not directly imply specific ways of arranging subject matter throughout individual processes of teaching and learning, as long as different processes meet the goals set by the standards in the end. The question whether using leading ideas for this limited objective is a sustainable use of this conception still remains. It could be argued that guidance by leading ideas is little more than lip service if it does not mean much more than acquiring a set of loosely grouped yet ultimately disbanded abilities and competencies.

Positively said, this more pragmatic account of fundamental ideas helped to reach some kind of consensus regarding a canon of ideas - at least at the level of the end of lower secondary education. This development had its particular prerequisites, as there are

(1) Shifting from fundamental ideas as rather general mathematical concepts, procedures and activities themselves to fundamental ideas as different perspectives of the discipline on reality, closely related to already well-established central topics of school mathematics.

(2) Restricting the use of fundamental ideas to conceptualizing what matters in the end.

It will be interesting to observe whether this consensus remains intact regarding the newly introduced standards at the upper secondary level, where the same set of leading ideas is used but the partitions and priorities implied by leading ideas and traditional curricular strands differ more notably ${ }^{10}$.

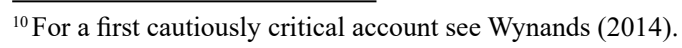




\section{Fundamental Ideas and Subject Matter Didactics: Interrelations and Differentiations}

This volume is dedicated to the specific tradition of subject matter didactics ("Stoffdidaktik") and there is little doubt that conceptions of fundamental ideas are deeply rooted within this tradition. One key issue of subject matter didactics is preparing mathematics for students. If one accepts that the benefits of analyzing the logical structure of the subject matter are limited for this purpose, achieving this goal involves a more elaborated process of "elementarization". This is the process of translating "mathematical concepts, principles, techniques, and reasoning methods from the forms in which they are discovered and then verified by formal reasoning to forms that can be learned readily by a broad audience of students" (Fey 1994, p. 22).

One problematic feature processes of elementarization are prone to is that the principles and strategies involved in these processes often stay implicit. We are rather confronted with the results of elementarization processes than with the processes, principles and strategies that lead to them. The formulation of didactic principles can be seen as an attempt to elaborate on elementarization strategies and to justify them against the background of theories from educational psychology, philosophies of mathematics and education and other neighboring fields of research ${ }^{11}$. Guidance by fundamental ideas is one such principle. However, as may have become apparent already, different conceptions of fundamental ideas throughout the different stages of the development discussed above vary to a considerable extent regarding the explicitness as well as the particular choice of background theories taken into account within these conceptions.

Embedding the discussion of fundamental ideas within subject matter didactics or relating both lines of research to each other faces another issue: To my understanding, subject matter didactics is less of a clear-cut research program with a mutually shared and explicitly stated theoretical basis, than more of a broader, theoretically somewhat heterogeneous approach mainly held together by focussing on the analysis of mathematical content for the purpose of preparing it for students. This approach has been the predominant approach in mathematics education research in German-speaking countries up until the $1970 \mathrm{~s}^{12}$ and it has been heavily contested as being a reductionist approach since then (cf. Steinbring 2011).

The following section of this article offers two approaches for relating the discussion about fundamental ideas with subject matter didactics. Firstly, I will choose Kirsch's (1977/ 2000) reflections on "simplification" and making mathematics education accessible for students as a starting point. In trying to answer what (potentially problematic) aspects of the German-language discussion about fundamental ideas may be associated with their background in subject matter didactics will then be broadened by integrating other accounts of subject matter didactics, some of them

\footnotetext{
${ }^{11}$ That is not to say that didactic principles do not have their own problematic features, for a critical account cf. Tietze (1994, pp. 43/44).

${ }^{12}$ It is even sometimes argued that "Stoffdidaktik" is simply synonymous of "Mathematikdidaktik" (didactics of mathematics/mathematics education research) up until the 1970 s - at least as far as secondary education is concerned.
} 
more critical towards this research approach in general. Secondly, I will compare fundamental ideas with "Grundvorstellungen" ", a second category deeply rooted within the subject matter didactics tradition. On the one hand, this category shares some of the objectives of fundamental ideas but on the other hand it has in many respects proven to be more open to an evolving understanding of the role of mathematical content knowledge in understanding and developing processes of mathematics teaching and learning and may be a particularly interesting point of reference for our future understanding of fundamental ideas.

\subsection{Relations to Subject Matter Didactics in General}

Broadly speaking, one may define the main objective of subject matter didactics as trying to better understand mathematics in order to make it understandable and better accessible for students. Kirsch (1977/2000) describes four ways in which subject matter didactics tries to make mathematics more accessible:

(1) by concentration on the mathematical heart of the matter,

(2) by including the "surroundings" of mathematics,

(3) by recognizing and activating pre-existing knowledge,

(4) by changing the mode of representation.

Of these four ways of making mathematics more accessible the first three are of particular interest for the development of fundamental ideas. Concentration on the mathematical heart of the matter is in its broadest sense the core objective of guidance by fundamental ideas, whereas fundamental ideas are in fact a possible conceptualization of what constitutes the heart of all mathematics. Although, if we take Kirsch more literally, this statement has to be refined. Kirsch (1977/2000) defines making accessible by concentration on the mathematical heart of the matter as

the view, that mathematics in its most mature form, that is, mathematics in the narrowest sense of the word, stripped of all its genetic elements and connections with reality, is the simplest mathematics. Working out the central concepts, generalizing, and emphasizing fundamental structures is a way of making mathematics more accessible.

While this view corresponds directly to early "New Math" interpretations of Bruner, neither the Meran reformists, nor Whitehead, nor the proponents of fundamental ideas in the third and fourth stage are solely (if at all) committed to this view. In fact, any of these conceptions places emphasis on either genetic elements or connections of mathematics to reality or both of those aspects (with Tietze, Klika \& Wolpers demarking an extreme case by introducing a particular subcategory of fundamental ideas for basic concepts, genetic elements and connections to reality, respectively). However, we would be wronging Kirsch here if we would not take his further elaboration on "the mathematical heart of the matter" into account. Kirsch argues that

\footnotetext{
${ }^{13}$ The term roughly translates to "basic notions" but will be kept German to ensure consistency across the articles in this volume.
} 
making accessible by concentrating on the heart of the matter cannot be achieved by "simplification of the deductive structure" alone, when in fact "structural simplification can make access more difficult" (ibid., p. 270). Early approaches of implementing fundamental ideas in the form of basic concepts and structures along the lines of the Bourbaki group may therefore be well intended but provide no royal road for making mathematics accessible to students according to Kirsch. Kirsch also concedes that "what the essence of a concept is may be hard to decide" and one has to take into account "above and beyond internal mathematical considerations $[\ldots]$ the pupils' background knowledge", notwithstanding the essence of a concept being "by no means merely a matter of taste" (ibid.).

The case of making accessible by including the "surroundings" of mathematics is a simpler one: Kirsch describes this way as "taking a broader view of mathematics which includes the origin of concepts and their relations to reality" (ibid., p. 271). Schreiber is especially concerned with the origins of concepts within everyday thinking and we already mentioned Heymann's assessment that conceptions of fundamental ideas widely agree upon their role as interfaces between mathematics and reality, this aspect even becoming the predominant one in the fourth phase of the development. Again, we may see early implementations of Bruner against the backdrop of "New Math" as the sole example where this aspect is widely neglected, although Bruner's call for early intuitive use of fundamental ideas and discovery learning would have provided quite a good reason for thoroughly examining the origins of concepts.

Making mathematics more accessible by recognizing and activating pre-existing knowledge is closely related to the spiral curriculum. If one wants to introduce basic ideas in an intuitive form early on and then proceed by revisiting them and "building upon them until the student has grasped the full formal apparatus that goes with them" (Bruner 1977, p. 19), one clearly has to recognize and activate pre-existing knowledge at those later stages. All concepts of the third stage relate in some way to the notion of the spiral curriculum: it is less important in the case of leading ideas of the national educational standards, where assessment of the outcomes of educational processes begins to dominate designing these processes as the prevalent use case for these ideas.

As far as ways of making mathematics more accessible are concerned, guidance by fundamental ideas is therefore firmly rooted in the tradition of subject matter didactics. As subject matter didactics was well established before the notion of fundamental ideas became more common, it may provide one possible explanation for the large resonance this notion found in the German-speaking community of mathematics education research. Analyzing the mathematical content, working out its logical structure and uncovering the origins of its central concepts were tasks this tradition of mathematics education research had already grown accustomed to and it was as well needed in both identifying fundamental ideas and in conceiving ways they could guide mathematics instruction.

Unfortunately, research about fundamental ideas also shares some of the more problematic aspects this line of research is prone to in general. Traditionally, subject matter analyses have been concerned with the scientific elaboration of schoolmathematical subject areas, therefore creating "heteronomous background theories" (Becker 1978) which show that mathematical knowledge as taught in schools can- 
in principle - be arranged in a logically consistent way and built upon unambiguous foundations (cf. Sträßer 1994). Such an effort becomes problematic when the worked out background theories become the sole background against which didactical questions are answered (cf. Steinbring 2011, pp. 45/46). While proponents of subject matter didactics usually agree that their background theories are "meant for the teacher" and should not be "mistaken for proposed classroom material" (Kirsch 2000, p. 272), Vollrath (1979) argues that the intended relation between background theories and classroom material often is not outlined sufficiently precise within subject matter didactics either.

Steinbring (2011, p. 46) asserts that - at least in its "fundamentalist form" conducted during the "New Math" period - subject matter didactics directly implied that the worked out background theories were "the central and crucial means [...] for steering and optimizing mathematical instruction, learning and understanding". He especially criticizes subject matter didactics for assuming that "mathematical knowledge - as researched and developed in the academic discipline - is unchanged and absolute" therefore being "dominated by too simple a model to solve didactic questions and research problems" (ibid., p. 45). Following Winter (1985) and Freudenthal (1973) Steinbring argues that such an approach is reductionist in that it fails to appropriately take into account both the relation of mathematics to the "outer-mathematical reality" (Winter 1985, p. 81, translated by Steinbring 2011) and "mathematics as an activity" (Freudenthal 1973, p. 114). Steinbring himself is committed to a view of different cultures or (in his own words) "institutional systems" (Steinbring 2011, p. 51) of mathematics that are to some degree independent of each other. Mathematical knowledge within the mathematics classroom, mathematics in everyday practices and mathematics as a scientific discipline are such systems or cultures in each of which mathematical knowledge has to be constructed socially and which are therefore independent of each other to some extent. According to Steinbring any attempt to understand and/or influence one of these systems (e.g. the mathematical classroom) has to be considered problematic if it does not take difference between these systems into account and simply tries to apply or superimpose the logic and inner workings from one of the other systems (e.g. mathematics as a scientific discipline). "New Math" can again be considered the prime example of such an undertaking, while subject matter didactics in general is at least prone to such a problematic view.

To what extent do these problems apply to different conceptions of fundamental ideas? I already mentioned that apart from early interpretations of Bruner against the background of "New Math" conceptions of fundamental ideas always include some considerations about the applications of mathematics, its roots in the realm of everyday thinking and activity. Especially Schreiber's conception conceptualizes fundamental ideas as a part of "mathematics as an activity", i.e. it focuses on processes of mathematization rather than on concepts and structures of "ready-made mathematics" (Freudenthal 1973, p. 114). Vollrath's and Steinbring's critique may still apply to conceptions of fundamental ideas from the third stage in respect to their focus on rather conceptual considerations. Both Schreiber and Schweiger initially considered fundamental ideas primarily as meta-concepts for teachers and curriculum designers, elements of a background theory, whose actual consequences for curriculum design and classroom practice again are not outlined precisely sharp, let alone leading to sys- 
tematic empirical evaluation. Although background theories of the third stage of the development of fundamental ideas discussed above are not as rigorously constructed and restricted to the logical structure of mathematical knowledge as they were during the "New Math" phase, those conceptions still adhere to the notion of mathematics as a unified, continually developing activity, at its heart guided by the same ideas, whether one looks at mathematics in the classroom or at the "frontiers" of the scientific discipline. While some considerations about different systems or cultures of mathematical practices to which different mathematical ideas may be central have been developing since the beginning of the second stage, the core assumption that there are some ideas central to any culture or system of mathematics at any level of its development simply must be maintained - otherwise, one would have to abandon any notion of fundamental ideas. As far as I can tell, Bruner's "bold hypothesis" ("the intellectual activity is the same") has not been rejected in this regard-yet little has been done to prove or disprove it on sound empirical grounds.

\subsection{Relations to Grundvorstellungen}

Grundvorstellungen (GV) as a second category deeply rooted within the subject matter didactics tradition, while sharing some of the objectives of fundamental ideas, have in many respects proven to be more open to an evolving understanding of the role of mathematical content knowledge in understanding and developing processes of mathematics teaching and learning.

GVs are "mathematical ideas" comparable to fundamental ideas to that effect that both of these constructs imply that there is a mathematical core, a gist of the matter, or literally: an idea one simply has to get, to understand what the related mathematical content is essentially about and to make appropriate use of it (cf. Vohns 2010). But GVs are local ideas, they try to make one particular concept, one particular operation or one particular method accessible through providing one or usually more than one model which then act together as different metaphorical approaches to the gist of this particular concept, operation or method, respectively. The main didactical objective of GVs has been and still is considered primarily to describe "adequate real-life contexts which represent the 'heart' (or 'essence') of the respective mathematical contents in a way which is understandable for the student" (vom Hofe 1998, p. 320), to make a mathematical concept applicable to real-world situations "by recognizing corresponding structures in real-life contexts or by modelling a real-life situation with the aid of the mathematical structure" (ibid.). One might even say that any conception of mathematical learning that aims to provide any conceptual or procedural understanding at all (i.e. that is not solely committed to instrumental understanding) is to some effect concerned with GVs or a functional equivalent.

Fundamental ideas on the other hand have always been conceptualized as overarching meta-concepts that are meaningful for a broader area of mathematical content. They should be effective at different levels of mathematical activities, giving an understanding of the gist of the whole area of mathematical content in question or even mathematics in general. Every conception of fundamental ideas therefore draws attention to interconnections of mathematical knowledge. It brings forward what can be understood as the "common core" of a whole set of mathematical con- 
cepts, procedures and methods in this area and it rests on the assumption that to really understand mathematics - or better yet: to make it accessible to students as a teacher or curriculum designer-one has to recognize these interconnections and commonly shared features of the respective concepts, procedures and methods (cf. Vohns 2010). But that is an assumption that goes above and beyond the assumption that one particular concept or procedure has to be connected to corresponding contexts or structures in real life. It is also considerably more difficult to design empirical research that substantiates or disproves such assumptions, as they are not contained to a well-defined point within a learning process but rather assumptions about its long-term development.

Secondly, fundamental ideas, while often conceptualized as harking back to archetypes in everyday thinking and activities, and, often conceptualized as interfaces between mathematics and reality, have not been restricted to this particular aspect at least up until the fourth stage of the development as described above. The whole notion of "guidance by fundamental ideas" - as already mentioned a few times above-suffers from a relatively vague formulation of its exact didactical objective. Conceptions of GVs clearly assume that for a mathematical concept or procedure to be applicable to real-life situations students have to acquire appropriate GVs. The question is not whether they should acquire these models but rather which GVs have to be acquired and to what extent theoretically conceptualized, didactically intended GVs allow for individual adoptions and variations (cf. Vohns 2010, pp. 233-235). A similar certainty is not to be found in the context of fundamental ideas, where it is yet unclear which guidance should exactly be provided whom.

One possible way discussed to overcome the particular problems of fundamental ideas is linking research about fundamental ideas with research about GVs or similar notions of local ideas or subconcepts. For example, Kröpfl et al. (2000) discuss local meanings and central actions related to central ideas of stochastic. Local meanings act as functional equivalent of GVs to that effect that they are local embodiments of the central ideas which should give an idea of the meaning of a particular concept or procedure in real-life contexts. For example, the authors discuss replacing "an entire (often confusing) list of data by means of a single 'representative', 'typical' or 'average' value" (ibid., p. 35) as a local meaning of different measures of central tendency related to the central idea of data condensation.

For my own part, I have discussed ways of relating fundamental ideas and GVs and similar subconcepts in both Vohns (2005) and Vohns (2007) with a focus on arithmetic and geometry and the fundamental ideas of number and measurement, respectively. The approach suggested in these papers restricted the use of fundamental ideas to a rather analytical one, i.e. using fundamental ideas for identifying appropriate GVs and local subject-specific strategies students should (or do actually) achieve. Such an approach has the benefit of a rather clearly outlined didactical objective-students should acquire important GVs and local strategies. It might be considered deficient if one adheres to the notion of fundamental ideas as an important content to be learned in its own right. In Vohns (2010) I began to embrace a similar perspective, based upon the argument that for mathematics instruction to be relevant as background knowledge for students' later lives a principle understanding of the inner workings of mathematics and the perspectives on reality it allows for has to be achieved that 
goes beyond the mathematical procedures one is able to conduct by oneself. If one considers fundamental ideas relevant in this respect, strictly decomposing fundamental ideas to a set of GVs and local subject-specific strategies and afterwards just involving students with these local representations has to be considered insufficient. In Vohns (2010) it is therefore further argued that in addition to designing mathematical courses in a way that proposed fundamental ideas can be experienced by means of GVs and local subject-specific strategies, opportunities to discuss, negotiate and reflect on fundamental ideas themselves are as well needed, i.e. opportunities to think and talk about what is (or better yet: was in retrospect) central to a particular unit and how it relates to earlier mathematical experiences.

\section{Outlook: Recent Developments and Closing Remarks}

The present article was aimed at familiarizing the English-speaking reader with the discussion about and the development of fundamental ideas as a guiding category for mathematics education research. As far as the broader notion is concerned "that education should not focus on subordinate matter, but on the central ideas of a discipline" (Bender and Schreiber 1980, p. 75) there is little doubt that this notion is mutually shared and will stay relevant for mathematics education.

The theoretical discussion about fundamental ideas as a didactical category has become less intense and few if any new attempts at conceptualizing fundamental ideas of mathematics as a whole have been undertaken since Heymann and the National Educational Standards for Mathematics in Grades 5-10. However, I consider the discussion about central ideas of specific areas of mathematics a topic that is still important to mathematics education research. Leading ideas as designations of areas of phenomena in which mathematics is applicable still leave enough room to discuss why mathematics is applied in these areas and how it becomes useful in these areas. Yet, in answering these questions, central ideas of the respective areas inevitably become relevant.

More recent works on such central ideas include e.g. Biehler and Burrill (2011), who discuss how different perspectives on statistics and statistics teaching lead to different ideas "that seem to be fundamental for understanding and being able to use statistics in the workplace, in personal lives, and as citizens" (ibid., p. 57). Leuders et al. (2011) are interested in the role of core ideas of less broad areas of school mathematics for a design research program aimed at the lower secondary school years. In this approach the more objectivistic understanding of fundamental ideas is confronted with the more subjective understanding of core ideas following the principle of dialogic learning (cf. Gallin 2012).

The idea of more personal, individualized accounts of fundamental ideas has also grown on Schweiger $(2005,2010)$, who claims that "the most important point is that student teachers, teachers, and teacher educators consider the possibility of finding such fundamental ideas. This process clearly should involve a communicative structure and could take place in seminars, during in-service education, and very important during casual discussions" (Schweiger 2005, p. 71). In Vohns (2010) it is suggested to consider proposed fundamental ideas opportunities to experience coherence and 
continuity, which students should negotiate about and which have to be thought of as an offer they actually can refuse on grounds of reflection upon their own experience of socially constructing mathematical knowledge in the classroom.

ABCmath (cf. Kuntze et al. 2011; Kuntze and Dreher 2011) was a trinational project for raising "awareness of big ideas in mathematics" which again chose a middle ground between more general fundamental ideas and strictly local conceptions such as GVs. The unique qualities within this approach towards "awareness for big ideas" are that the approach both aims directly at designing learning opportunities fostering reflection on big ideas for students as well as prospective or active teachers of mathematics and that the "big ideas" considered lay great emphasis on establishing networks between mathematical topics from different mathematical content strands. Kuntze and Dreher (2011, p. 16) also contains the notion of fundamental ideas of mathematics education (i.e. pedagogical content knowledge) for teachers. Similarly, Rezat (2012) suggests fundamental ideas of mathematics education as a way of reflection on theories in mathematics education research, Rezat et al. (2014) further explore this idea choosing "transformation" as an idea considered fundamental within mathematics education research.

The diversification of approaches to identify and conceptualize the didactical objectives of fundamental ideas currently pursued might be considered a much needed countermeasure against the one-sidedness of simply trying to superimpose basic ideas, concepts and structures of the scientific discipline upon mathematics instruction. The ongoing trend towards less "big", less general ideas (that is to fundamental ideas that only cover specific content areas or specific ideas for networking different areas well coverable within a single teaching unit) is without a doubt helpful in more clearly working out teaching examples and in carrying out empirical studies e.g. in design research settings. On the other hand, such ideas suffer inevitably from the problem that either the amount of fundamental ideas becomes rather large or otherwise, if only a few ideas are chosen (e.g. for the matter of making at least some interconnections between different areas of mathematical content tangible) the resulting sets sometimes convey a rather eclectic impression.

Therefore, the question still remains, whether mathematics instruction should also aim at "larger" ideas, which try to provide students with an understanding of the "nature of mathematics" (cf. Müller-Hill 2015) - and how such a goal can be achieved. Questions about the nature of mathematics (and questions about the ends to which we teach mathematics in school) will always remain normative questions because the answers we may find will always depend on which perception of mathematics we deem adequate as far as school mathematics is concerned. As long as we consider fundamental ideas related to and helpful in answering these questions, the discussion about fundamental ideas will remain relevant to mathematics education.

Open Access This article is distributed under the terms of the Creative Commons Attribution License which permits any use, distribution, and reproduction in any medium, provided the original author(s) and the source are credited. 


\section{References}

Baptist, P., \& Winter, H. (2001). Überlegungen zur Weiterentwicklung des Mathematikunterrichts in der gymnasialen Oberstufe. In H. E. Tenorth (Ed.), Kerncurriculum Oberstufe (pp. 54-76). Weinheim: Beltz.

Becker, G. (1978). Über Hintergrundtheorien geometrischer Schulkurse. Mathematica Didactica, 1(1), 13-20.

Bender, P. (1978). Umwelterschließung im Geometrieunterricht durch operative Begriffsbildung. Der Mathematikunterricht, 24(5), 25-87.

Bender, P. (1983). Zentrale Ideen der Geometrie für den Unterricht in der Sekundarstufe I. Beiträge zum Mathematikunterricht, 1983, 8-17.

Bender, P., \& Schreiber, A. (1980). The principle of operative concept formation in geometry teaching. Educational Studies in Mathematics, 11(1), 59-90.

Bender, P., \& Schreiber, A. (1985). Operative Genese der Geometrie. Wien: Hölder-Pichler-Tempsky \& Teubner.

Biehler, R., \& Burrill, G. (2011). Fundamental statistical ideas in the school curriculum and in training teachers. In C. Batanero, G. Burill, \& C. Reading (Eds.), Teaching statistics in school mathematicschallenges for teaching and teacher education: A joint ICMI/IASE study (pp. 57-69). New York: Springer.

Biehler, R., \& Peter-Koop, A. (2008). The Development of Mathematics Education as a Scientific Discipline-Some Reflections from a German Perspective. Paper presented at the Symposium on the Occasion of the 100th Anniversary of ICMI (Rome, 5-8 March 2008). http://www.unige.ch/math/ EnsMath/Rome2008/WG5/Papers/BIEPK.pdf. Accessed 28 Jan 2016.

Biermann, H. R., \& Jahnke, H. N. (2014). How eighteenth-century mathematics was transformed into nineteenth-century school curricula. In S. Rezat, M. Hattermann, \& A. Peter-Koop (Eds.), Transformation - a fundamental idea of mathematics education (pp. 5-28). New York: Springer.

Bishop, A. J. (1988). Mathematical enculturation. Dordrecht: Kluwer.

Bruner, J. (1960). The process of education. Cambridge: Harvard university press.

Bruner, J. (1977). The process of education (second, revised edition). Cambridge: Harvard university press.

Damerow, P. (1977). Die Reform des Mathematikunterrichts in der Sekundarstufe I-Band 1: Reformziele, Reform der Lehrpläne. Stuttgart: Klett.

Fey, J. T. (1994). Eclectic approaches to elementarization: Cases of curriculum construction in the United States. In R. Biehler, R. W. Scholz, R. Sträßer, \& B. Winkelmann (Eds.), Didactics of mathematics as a scientific discipline (pp. 15-26). New York: Kluwer Academic Publishers.

Fischer, R. (1976). Fundamentale Ideen bei den reellen Funktionen. Zentralblatt für Didaktik der Mathematik, 3(8), 185-192.

Fischer, R. (1985). Unterricht als Prozeß der Befreiung vom Gegenstand-Visionen eines neuen Mathematikunterrichts. Journal für Mathematik-Didaktik, 5(1-2), 51-85.

Freudenthal, H. (1973). Mathematics as an educational task. Dodrecht: D. Reidel Publishing Company.

Freudenthal, H. (2002). Revisiting mathematics education-China lectures. Dodrecht: Kluwer Academic Publishers.

Führer, L. (1997). Pädagogik des Mathematikunterrichts_Eine Einführung in die Fachdidaktikfür Sekundarstufen. Braunschweig: Teubner.

Gallin, P. (2012). Dialogic learning - from an educational concept to daily classroom teaching. In P. Baptist, \& D. Raab (Eds.), Implementing Inquiry in Mathematics Education (pp. 23-34). http://fibonacci. uni-bayreuth.de/resources/resources-for-implementing-inquiry.html. Accessed 28 Jan 2016.

Gutzmer, A. (1905). Bericht betreffend den Unterricht in der Mathematik an den neunklassigen höheren Lehranstalten-Reformvorschläge von Meran. Zeitschrift für den mathematischen und naturwissenschaftlichen Unterricht aller Schulgattungen, 36, 543-553.

Heymann, H. W. (1996). Allgemeinbildung und Mathematik. Weinheim: Beltz.

Heymann, H. W. (2003). Why teach mathematics? A focus on general education. Dodrecht: Kluwer Academic Publishers.

Humenberger, H., \& Reichel, H.-C. (1995). Fundamentale Ideen der Angewandten Mathematik und ihre Umsetzung im Unterricht. Mannheim: Spektrum Akademischer Verlag.

Jung, W. (1978). Zum Begriff einer mathematischen Bildung. Rückblick auf 15 Jahre Ma-thematikdidaktik. Mathematica Didactica, 1(3), 161-176. 
Kirsch, A. (2000). Aspects of simplification in mathematics teaching. In I. Westbury, S. Hopmann, \& K. Riquarts (Eds.), Teaching as a reflective practice - the German didactic tradition (pp. 267-284). Mahwah: Lawrence Erlbaum Associates. (Reprinted from: Proceedings of the third international congress on mathematical education, pp. 98-120, by H. Athen, \& H. Kunle H (Eds.), 1977, Karlsruhe: Zentralblatt für Didaktik der Mathematik).

Klafki, W. (2000). The significance of classical theories of bildung for a contemporary concept of Allgemeinbildung. In I. Westbury, S. Hopmann, \& K. Riquarts (Eds.), Teaching as a reflective practicethe German didactic tradition (pp. 85-108). Mahwah: Lawrence Erlbaum Associates.

KMK-Kultusministerkonferenz der Länder. (2004). Bildungsstandards im Fach Mathematik für dem Mittleren Bildungsabschluss. Beschluss vom 4.12.2003. Neuwied: Luchterhand.

Kröpfl, B., Peschek, W., \& Schneider, E. (2000). Stochastik in der Schule: Globale Ideen, lokale Bedeutungen, zentrale Tätigkeiten. Mathematica Didactica, 23(2), 25-57.

Krüger, K. (2000). Erziehung zum funktionalen Denken: Zur Begriffsgeschichte eines didaktischen Prinzips. Berlin: Logos.

Kuntze, S., \& Dreher, A. (Eds.). (2011). Big Ideas im Zentrum des Mathematikunterrichts: Fachdidaktischer Hintergrund, Anregungen für die Unterrichtspraxis und Materialien für schüler(innen)zentrierte Lernumgebungen. Ludwigsburg: Verlag Pädagogische Hochschule Ludwigsburg.

Kuntze, S., Lerman, S., Murphy, B., Siller, H.-S., Kurz-Milcke, E., Winbourne, P., Vogl, C., Dreher, A., Wagner, A., Wörn, C., Schneider, S., \& Fuchs, K.-J. (2011). ABCmaths: Awareness of Big Ideas in Mathematics Classrooms. Final Report, Public Part. http://eacea.ec.europa.eu/llp/project_reports/ documents/comenius/all/com mp 503215 abcmaths.pdf. Accessed 28 Jan 2016.

Lenné, H. (1969). Analyse der Mathematikdidaktik in Deutschland. Stuttgart: Klett.

Leuders, T., Hußmann, S., Barzel, B., \& Prediger, S. (2011). "Das macht Sinn!”-Sinnstiftung mit Kontexten und Kernideen. Praxis der Mathematik in der Schule, 53(37), 2-9.

Müller-Hill, E. (2015). Making it explicit? Zum Lehren und Lernen von mathematischen Leitideen und "nature of science" als Aspekte mathematischer bzw. naturwissenschaftlicher Grundbildung. Mathematica Didactica, 38 (2), 132-172.

Neubrand, M., Biehler, R., Blum, W., Cohors-Fresenborg, E., Flade, L., Knoche, N., Lind, D., Loeding, W., Moeller, G., \& Wynands, A. (2001). Grundlagen der Ergänzung des internationalen PISA-Mathematik-Tests in der deutschen Zusatzerhebung. Zentralblatt für Didaktik der Mathematik, 33(2), 45-59.

OECD. (2000). Measuring student knowledge and skills. The PISA 2000 assessment of reading, mathematical and scientific literacy. Paris: OECD Publishing.

OECD. (2003). The PISA assessment framework-mathematics, reading, science and problem solving knowledge and skills. Paris: OECD Publishing.

OECD. (2013). PISA 2012 assessment and analytical framework-mathematics, reading, science, problem solving and financial literacy. Paris: OECD Publishing.

Peschek, W. (2005). Reflexion und Reflexionswissen in R. Fischers Konzept der höheren Allgemeinbildung. In K. Lengnink, \& F. Siebel (Eds.), Mathematik präsentieren, reflektieren, beurteilen (pp. 55-68). Darmstadt: Allgemeine Wissenschaft.

Prediger, S. (2014). Discussion of part III: Fundamental ideas of didactics - reactions to the suggested meta-theoretical construct for reflecting and connecting theories. In S. Rezat, M. Hattermann, \& A. Peter-Koop (Eds.), Transformation-A fundamental idea of mathematics education (pp. 387-396). New York: Springer.

Rezat, S. (2012). Fundamental ideas: A means to provide focus and identity in didactics of mathematics as a scientific discipline? In T. Tso (Ed.), Proceedings of the 36th Conference of the International Group for the Psychology of Mathematics Education (vol. 4, pp. 3-10). Taipei: PME.

Rezat, S., Hattermann, M., \& Peter-Koop, A. (Eds.). (2014). Transformation-a fundamental idea of mathematics education. New York: Springer.

Schreiber, A. (1979). Universelle Ideen im mathematischen Denken-ein Forschungsgegenstand der Fachdidaktik. Mathematica Didactica, 2, 165-171.

Schreiber, A. (1983). Bemerkungen zur Rolle universeller Ideen im mathematischen Denken. Mathematica Didactica, 6, 65-76.

Schreiber, A. (2011). Begriffsbestimmungen. Berlin: Logos.

Schupp, H. (1984). Optimieren als Leitlinie im Mathematikunterricht. Mathematische Semesterberichte, 31(1), 59-76.

Schweiger, F. (1982). Fundamentale Ideen der Analysis und handlungsorientierter Unterricht. Beiträge zum Mathematikunterricht, 16, 103-111. 
Schweiger, F. (1992). Fundamentale Ideen. Eine geistesgeschichtliche Studie zur Mathematikdidaktik. Journal für Mathematik-Didaktik, 13(2/3), 199-214.

Schweiger, F. (2005). Fundamental ideas - a bridge between mathematics and mathematical education. In J. Maaß \& W. Schlöglmann (Eds.), New mathematics education research and practice (pp. 63-74). Rotterdam: Sense Publishers.

Schweiger, F. (2010). Fundamentale Ideen. Herzogenrath: Shaker Verlag.

Schwill, A. (1993). Fundamentale Ideen der Informatik. Zentralblatt für Didaktik der Mathematik, 93(1), 20-31.

Steinbring, H. (2011). Changed views on mathematical knowledge in the course of didactical theory development: Independent corpus of scientific knowledge or result of social constructions? In T. Rowland \& K. Ruthven (Eds.), Mathematical knowledge in teaching (pp. 43-64). New York: Springer.

Sträßer, R. (1994). A propos de la transposition franco-allemande en didactique des mathématiques. In M. Artigue, R. Gras, C. Laborde, \& P. Tavignot (Eds.), Vingt Ans de Didacttique ded Mathématiques en France (pp. 161-176). Grenoble: La Pensée Sauvage.

Takaya, K. (2008). Jerome Bruner's theory of education: From early Bruner to later Bruner. Interchange, 39(1), 1-19.

Thom, R. (1973). Modern mathematics: Does it exist? In A. G. Howson (Ed.), Developments in mathematical education (pp. 194-209). Cambridge: Cambridge University Press.

Tietze, U. P. (1979). Fundamentale Ideen der Linearen Algebra und Analytischen Geometrie. Mathematica Didactica, 2, 137-163.

Tietze, U. P. (1994). Mathematical curricula and the underlying goals. In R. Biehler, R. W. Scholz, R. Sträßer, \& B. Winkelmann (Eds.), Didactics of mathematics as a scientific discipline (pp. 41-53). New York: Kluwer Academic Publishers.

Tietze, U. P., Klika, M., \& Wolpers, H. (1982). Didaktik des Mathematikunterrichts in der Sekundarstufe II. Braunschweig: Vieweg.

Tietze, U. P., Klika, M., \& Wolpers, H. (1997). Didaktik des Mathematikunterrichts in der Sekundarstufe II. Band 1: Fachdidaktische Grundfragen, Didaktik der Analysis (second edition). Braunschweig: Vieweg.

Vohns, A. (2005). Fundamentale Ideen und Grundvorstellungen: Versuch einer konstruktiven Zusammenführung am Beispiel der Addition von Brüchen. Journal für Mathematik-Didaktik, 26(1), 52-79.

Vohns, A. (2007). Grundlegende Ideen und Mathematikunterricht. Entwicklung und Perspektiven einer fachdidaktischen Kategorie. Norderstedt: Books On Demand.

Vohns, A. (2010). Fünf Thesen zur Bedeutung von Kohärenz- und Differenzerfahrungen im Umfeld einer Orientierung an mathematischen Ideen. Journal für Mathematik-Didaktik, 31(2), 227-255.

Vollrath, H.-J. (1979). Die Bedeutung von Hintergrundtheorien für die Bewertung von Unterrichtssequenzen. Der Mathematikunterricht, 25(5), 77-89.

vom Hofe, R. (1998). On the generation of basic ideas and individual images: Normative, descriptive and constructive aspects. In A. Sierpinska \& A. J. Kilpatrick (Eds.), Mathematics education as a research domain: A search for identity (pp. 317-331). Dodrecht: Kluwer Academic Publishing.

Whitehead, A. N. (1911). An Introduction to Mathematics. Cambridge: Cambridge University Press.

Whitehead, A. N. (1913). The mathematical curriculum. Mathematical gazette, 7, 87-94. (Reprinted in Whitehead 1967, pp. 77-90).

Whitehead, A. N. (1916). The aims of education - a plea for reform. Mathematical gazette, 8, 191-203. (Reprinted in Whitehead 1967, pp. 1-14).

Whitehead, A. N. (1967). The aims of education and other essays. New York: The Free Press. (Reprinted from ibid. New York: MacMillan Company, 1929).

Winter, H. (1985). Reduktionistische Ansätze in der Mathematikdidaktik. Der Mathematikunterricht, 5, $75-78$.

Winter, H. (n. d.). Fundamentale Ideen in der Grundschule. http://www.schulabakus.de/Wechselspiele/ winter-ideen.html. Accessed 28 Jan 2016.

Wittenberg, A. I. (1963). Bildung und Mathematik. Stuttgart: Klett.

Wittmann, E. C. (1974). Grundfragen des Mathematikunterrichts. Braunschweig: Vieweg.

Wolters, G. (1988). Hugo Dingler. Science in Context, 2(2), 359-367.

Wynands, A. (2014). Mathematische (Basis-)Kompetenzen im Abitur. Mitteilungen der Gesellschaft für Didaktik der Mathematik, 97, 19-23. 